\title{
Nuclear disarmament
}

SIR - To be successful, any scheme for multilateral disarmament should proceed by small steps, should convince both sides that each has bettered the other and, most importantly, should not become embroiled in the difficulties of weapon comparison. I propose a mechanism which has these three characteristics. Indeed, it can turn to advantage the inevitable differences of opinion about weapons of the two sides. It is based on the "I cut - you choose" rule by which children can divide a cake.

Each side begins by assigning a number to each separable nuclear device in its armoury. This number, the "military value percentage", is chosen by the weapon owner to represent his view of the usefulness of the item as a part of his entire inventory. The sum of all the numbers of each side is equal to one hundred. To take an example, if the Soviet Union decided that the 350 missiles in the SS-20 system represented, say, 15 per cent of its nuclear strength then the military value of each would be 0.04292 per cent.

It would be extraordinary if the values of usefulness chosen by one side were in exact agreement with the magnitude of threat felt by the other. Indeed, we may expect that the weapons with accurate terminal guidance and short launch times, which are suitable for pre-emptive first strikes, will induce a feeling of threat in their victims which is much greater than the feeling of comfort they offer to their owners. On the other hand, second-strike weapons are valuable deterrents and provide a large feeling of security, but do not pose a threat in proportion. This difference of opinion provides the incentive for the disarmament process and ensures that both sides can believe that they have secured advantage.

The first reduction should be very small. Let us suppose that it is a step of about 1 per cent. Each side picks from the list of its opponent the most threatening items with total military value percentage not exceeding this "table limit". The selections may be announced simultaneously and small differences carried forward as credits for a second round.

If the United States happened to decide that the SS-20 was the most serious threat, they would request as a first move that the number of missiles be reduced by 23 . Meanwhile the Soviets would pick the most threatening 1 per cent of weapons from the US list. The United States would be quite indifferent about the Soviet choice because the numbers would have been chosen to make any 1 per cent selection equal, in their view, to any other.

Both sides will think they benefit from this exchange by an amount which depends on the ratio of perceived threat removed to perceived protection lost. The absolute, as opposed to the relative, magnitude of the reductions of each side, measured in terms of fire-power or lethality, will be greater for the power with the greater original armoury. But as both sides argue that the other has the excess they can hardly object to this feature of the scheme.

The problem of verification is common to all disarmament plans. A necessary assumption for any scheme is that both sides have reasonably accurate knowledge of the weapon systems of their opponents. If the reductions proceed by small, slow steps, then neither side need fear that its national security has been greatly endangered if verification goes wrong. But if a side is sincere about its wish to disarm, it can use the interpretation of verification procedures to send messages about its sincerity and entice the other side to continue.

Either side may wish to distort the percentage values it declares. But because the sum total is always equal to one hundred a reduction is quite legitimate but the ploy may backfire and lead to the loss of good weapons at less than their true value. It is also possible to design rules which allow updating of weapons. For example, if Side A insists on the introduction of some new missiles, it may do so provided that it also declares a military value percentage for it. Side B may then, without loss to its armoury, remove items to that same value from any part of Side A's inventory including the new ones. Side A will not want the new ones to be instantly lost and so will have to put a higher than true value on them. It will therefore have to give up rather more of its obsolete inventory. This rule would encourage the evolution of new weapons which provide high perceived security for low perceived threat - a most desirable feature.

\section{Department of Mechanical} STEPHEN SALTER

\section{Engineering,}

University of Edinburgh,

Edinburgh, UK

\section{Page charge revolt?}

SIR - The problem of discrimination by journals against impecunious authors is a serious one. It is a moral issue as much as a practical one: should ability of the author to pay be as important as scientific merit in accepting a paper for publication? Most journals require both, so each has an equivalent veto.

A journal can argue that it can publish less if it has less income, can charge less to subscribers if it collects from authors, and that authors who can afford to pay page charges often do not do so when the charges are voluntary. These problems are real ones, but do they really outweigh the denial of the possibility of publication to those unable to pay for it?

It is not adequate to say, as a few journals do, that "in exceptional circumstances" page charges will be waived. Be- ing impecunious is no longer exceptional, if it ever was. Neither is it adequate to require membership in a society even for authors marginal to it or unable to pay. And giving special treatment to those who pay of course again raises money to the rank of merit.

Publishers are not likely to give credit on page charges to referees (Nature 2 February, p.408), and anyway this would not help other impecunious authors. For the past decade I have neither submitted papers to, nor refereed for, any journal which practises financial discrimination.

It is often convenient to publish in discriminatory journals, and often these have good reputations scientifically. But if even those of us who can pay do not help such journals, and tell them why, we may be able to correct a serious iniquity.

LEIGHM. VAN VALEN

\section{Biology Department (Whitman),}

University of Chicago,

Chicago, Illinois 60637, USA

\section{Opposite to placebo}

SIR - L.J. Barrie (Nature 16 February, p.590) bemoans the lack of a term the opposite of a placebo: a harmless object producing a harmful effect if the receipient believes it to be noxious. Surely, the word is "antiplacebo". Some examples: the quite serious effect the bite of a harmless snake can produce if the victim believes it to be poisonous, or the bite of a poisonous snake when no venom has been injected into the wound. "Pointing the finger", curses, prophecies of evil, are of this nature. As a rule, the antiplacebo is not an object, like a pill; its potency is based entirely on its psychological effect, but so, in reality, is that of the placebo. STEPHENSEELY University of Manchester Medical School, Manchester MI3 9PT, UK

SIR - "Garblow" is an unfortunate proposal for a word to express the opposite of a placebo. "Antiplacebo", used by the late Gregory Bateson to describe a cancer diagnosis, has the advantage of suggesting its meaning. Shorter and equally Latin would be "displacebo".

PHILIP J. STEWART

Commonwealth Forestry Institute,

South Parks Road, Oxford $O X 13 R B, U K$

SIR - "Garblow" is an unnecessary dysphemism for "nocebo" to define "a harmless substance which produces harmful effects when the patient believes it to be toxic". "Nocebo" was introduced at least 15 years ago (G. Herzhaft, "L'Effet nocebo" Encéphale 58, 486; 1969).

M.J. Barrie also states that little attention has been paid to the harmful effects of placebos. In fact, Wolf (Pharmac. Rev. 11, 689-701; 1959) and Honigfelt (Dis. Nervous Syst. 25, 145-156; 1964) each cite 10 references to them. ARTHUR CHERKIN Veterans Administration Medical Center, Sepulveda, California 91343, USA 